\title{
Repeatability of the moments of the truncated forced expiratory spirogram
}

\author{
MR MILLER, AC PINCOCK \\ From the University of Birmingham, Department of Medicine, Queen Elizabeth Hospital, Birmingham
}

ABSTRACT It is proposed that if the spirogram is truncated for moment analysis, this should be done with respect to volume and not time. Errors are incurred when the moments of one spirogram are compared with those of another. These errors are maximal with no truncation and are reduced by truncation. A method is described for deriving sequential truncated moments of the forced expiratory spirogram. The repeatability and discriminatory power of the truncated moments were assessed over five consecutive days in 21 symptom-free subjects and were compared with conventional spirometric tests. The first and second moments about the origin of the spirogram $\left(\alpha_{1}\right.$ and $\left.\alpha_{2}\right)$, the moment ratio $\left(\sqrt{ } \alpha_{2} / a_{1}\right)$ and the forced expiratory time to truncation (FET) are progressively less repeatable within individuals the later the truncation point. The discriminatory power of $\alpha_{1}$ and $\alpha_{2}$ and FET declines with later truncation but the discriminatory power of the moment ratio is maximal with truncation at $85 \%$ forced vital capacity (FVC) and diminishes sharply if truncation is beyond $95 \%$ FVC. At $75 \%$ FVC truncation $\alpha_{1}$ is as good as $\mathrm{FEV}_{1} \%$ in discriminating between our subjects, whereas $\alpha_{1}$ at $100 \% \mathrm{FVC}$ is only half as good as $\mathrm{FEV}_{1} \%$. The moment ratio at $90 \% \mathrm{FVC}$ truncation is highly reproducible (mean within person coefficient of variation $2 \cdot 1 \%$ ), has important discriminatory power and is little influenced by events early in the spirogram (correlation with $\mathrm{FEV}_{1} \% \mathrm{r}=-0.61$, $\mathrm{p}<0.001$ ). The moment ratio at $90 \%$ of FVC has attributes which may be useful in detecting early airway obstruction and its further study is warranted in order to establish its normal range and predictive value.

Moment analysis of distributions is widely used in statistics. The " $r$ " th moment of a distributed variable is the average " $r$ " th power of the variable. The variable may be measured as its value relative to the origin of the distribution or relative to a point within the distribution (for example, the mean). For any distribution the first moment about the origin $\left(\alpha_{1}\right)$ is the mean and the second moment about the mean $\left(\mu_{2}\right)$ is its variance with respect to the mean. The spirogram can be considered as a cumulative distribution of transit times of the lung and its $\alpha_{1}$ is the mean time taken for increments of gas to be expired (mean transit time). For the spirogram, $a_{r}$ is given by

$\alpha_{\mathrm{r}}=\int_{0}^{\mathrm{v}} \frac{\mathrm{t}^{\mathrm{r}} \mathrm{dv}}{\mathrm{V}}$

where " $t$ " is the mean time taken for volume increments " $d v$ " to be expired and " $V$ " is the volume expired. It has been proposed that $\alpha_{1}$ is a sensitive test of lung function ${ }^{1-3}$; its merits are that it is standardised for lung volume and is sensitive to the whole spirogram.

Any satisfactory test of lung function should be repeatable within individuals and be able to detect true differences between individuals. The forced expiratory time (FET) is known to be highly variable within individuals ${ }^{4}$ and $\alpha_{r}$ is dependent on FET. The moments can be derived up to any point along the spirogram by integrating only up to that point (the truncation point) to derive $a_{r}$. These truncated moments can be from a spirogram truncated with respect to time or volume. We have undertaken a study to compare the repeatability of the moments of the full spirogram with the moments of the truncated spirogram to see if the latter were less variable within individuals and still able to detect differences between individuals. Truncation of the spirogram after an arbitrary six seconds has been used as a means of standardising the moments. ${ }^{2} 6$ We first undertook a theoretical consideration of truncation to challenge this convention.

\section{Truncation}

A satisfactory convention for truncating the spirogram should also apply to all similarly shaped curves. Consider a single exponential model of the forced 
expiratory spirogram of the form

$$
\mathrm{v}=1-\mathrm{e}^{-\mathrm{kt}}
$$

where " $v$ " is the volume expired as a fraction of unity terminal volume, " $t$ " is the elapsed time, and " $k$ " is the reciprocal of the time constant. Then $\mathrm{t}=\mathrm{k}^{-1} \ln (1-\mathrm{v})^{-1}$ and $\mathrm{dv} / \mathrm{dt}=\mathrm{ke}^{-\mathrm{kt}}$.

So from equation (1),

$a_{\mathrm{r}}=\mathrm{k}^{-\mathrm{r}} \int_{0}^{\mathrm{V}}\left[\ln (1-\mathrm{v})^{-1}\right]^{\mathrm{r}} \frac{\mathrm{dv}}{\mathrm{V}}=\int_{0}^{\mathrm{T}} \mathrm{t}^{\mathrm{r}} \mathrm{ke}^{-\mathrm{kt}} \frac{\mathrm{dt}}{\mathrm{V}}$

From these integrals the moments can be derived at any time or volume of truncation.

$\sqrt{ } a_{2} / a_{1}$ (the moment ratio) is an index of the dispersion (on a log scale) of the time constants of curves of this type. We will subsequently use dispersion in this context to refer to dispersion on a log scale. For single exponentials with different time constants this dispersion will be constant, namely zero. Hence a satisfactory convention for truncating single exponentials should yield a constant moment ratio at equivalent truncation points despite changes in time constant.

Table 1 shows the moment ratio for four different single exponentials at different times and volumes of truncation. The moments for these curves were derived from equation (2) being standardised by the volume at truncation.

It can be seen from table 1 that with truncation with respect to volume the moment ratio is correctly found to be constant irrespective of the time constant. However with truncation with respect to time, the moment ratio varies with the time constant, erroneously implying that these single exponentials have differing dispersion of time constants. These observations are also true if the moments are standardised by terminal volume which can be deduced by dividing the moment ratios in table 1 by the square root of the volume at truncation.

Furthermore, the same results are obtained if a more complicated model simulation is used, such as that proposed by Permutt and Menkes. ${ }^{7}$ They compared the spirogram with a model composed of a mixture of an infinite number of exponentials whose time constants are log normally distributed. $\mu$ (the mean of the $\log$ of the time constants) and $\sigma$ (the standard deviation of the log of the time constants) describe this distribution and $\sigma$ defines the dispersion of the time constants.

Table 2 shows moment ratios (standardised by volume at truncation) derived for varying $\mu$ and $\sigma$ values, with truncation with respect to both terminal volume and time. If truncation is with respect to volume for constant $\sigma$ with varying $\mu$, the moment ratio is constant, thus correctly identifying these curves as having the same dispersion of time constants. However if truncation is with respect to time for constant $\sigma$ with varying $\mu$, the moment ratio varies, thus erroneously implying that these curves have differing dispersion of time constants. Therefore these curves can only be truncated with respect to volume if valid comparisons of the moments of one curve with another are to be made. Mathematical proof of these observations will be supplied by the authors on request.

Verification that these observations pertain to real spirograms requires the comparison of two spirograms with known identical dispersion of time constants. The only way to obtain two such spirograms is to produce a second spirogram from an

Table $1 \vee a_{2} / a_{1}$ for four exponentials of the form $v=1-e^{-k t}$

\begin{tabular}{|c|c|c|c|c|c|c|c|c|c|c|}
\hline \multirow{2}{*}{$\begin{array}{l}\text { Time constant } \\
\text { in seconds }\end{array}$} & \multicolumn{5}{|c|}{ Truncation at $\%$ terminal volume } & \multicolumn{5}{|c|}{ Truncation at time in seconds } \\
\hline & $20 \%$ & $40 \%$ & $60 \%$ & $80 \%$ & $100 \%$ & 2 & 4 & 6 & 8 & 10 \\
\hline 1.00 & $1 \cdot 1656$ & $1 \cdot 1802$ & $1 \cdot 2014$ & $1 \cdot 2383$ & 1.4142 & $1 \cdot 2589$ & $1 \cdot 3464$ & $1 \cdot 3922$ & 1.4085 & 1.4129 \\
\hline $1 \cdot 50$ & $1 \cdot 1656$ & $1 \cdot 1802$ & $1 \cdot 2014$ & $1 \cdot 2383$ & 1.4142 & $1 \cdot 2236$ & $1 \cdot 2921$ & $1 \cdot 3464$ & $1 \cdot 3812$ & $1 \cdot 3988$ \\
\hline $2 \cdot 00$ & $1 \cdot 1656$ & $1 \cdot 1802$ & $1 \cdot 2014$ & $1 \cdot 2382$ & $1 \cdot 4142$ & $1 \cdot 2058$ & $1 \cdot 2589$ & $1 \cdot 3073$ & $1 \cdot 3464$ & $1 \cdot 3742$ \\
\hline
\end{tabular}

Time constant $=1 / \mathrm{k}$.

Table $2 \sqrt{ } \alpha_{2} / \alpha_{1}$ for theoretical spirograms derived from a mixture of an infinite number of exponentials whose time constants are log normally distributed

\begin{tabular}{|c|c|c|c|c|c|c|c|c|c|c|}
\hline \multirow[t]{2}{*}{$\mu$} & \multicolumn{2}{|c|}{$\begin{array}{l}\text { Truncation at } 75 \% \text { of } \\
\text { terminal volume }\end{array}$} & \multicolumn{2}{|c|}{$\begin{array}{l}\text { Truncation at } 90 \% \text { of } \\
\text { terminal volume }\end{array}$} & \multicolumn{2}{|c|}{ No truncation } & \multicolumn{2}{|c|}{$\begin{array}{l}\text { Truncation at } \\
\text { three seconds }\end{array}$} & \multicolumn{2}{|c|}{$\begin{array}{l}\text { Truncation at } \\
\text { six seconds }\end{array}$} \\
\hline & $\sigma=0.5$ & $\sigma=1 \cdot 0$ & $\sigma=0.5$ & $\sigma=1 \cdot 0$ & $\sigma=0.5$ & $\sigma=1 \cdot 0$ & $\sigma=0.5$ & $\sigma=1.0$ & $\sigma=0.5$ & $\sigma=1 \cdot 0$ \\
\hline-0.5 & $1 \cdot 2504$ & $1 \cdot 3224$ & $1 \cdot 3199$ & $1 \cdot 4481$ & $1 \cdot 6025$ & $2 \cdot 3316$ & 1.4187 & 1.4935 & 1.5332 & $1 \cdot 6636$ \\
\hline 0.0 & $1 \cdot 2504$ & $1 \cdot 3224$ & $1 \cdot 3199$ & 1.4481 & $1 \cdot 6025$ & $2 \cdot 3316$ & $1 \cdot 3357$ & 1.4002 & 1.4531 & $1 \cdot 5362$ \\
\hline 0.5 & $1 \cdot 2504$ & $1 \cdot 3224$ & $1 \cdot 3199$ & 1.4481 & $1 \cdot 6025$ & $2 \cdot 3316$ & $1 \cdot 2718$ & $1 \cdot 3295$ & $1 \cdot 3660$ & 1.4334 \\
\hline $1 \cdot 0$ & $1 \cdot 2504$ & $1 \cdot 3224$ & $1 \cdot 3199$ & $1 \cdot 4481$ & $1 \cdot 6025$ & $2 \cdot 3316$ & $1 \cdot 2282$ & $1 \cdot 2774$ & $1 \cdot 2939$ & $1 \cdot 3544$ \\
\hline
\end{tabular}

$\mu=$ the mean of the $\log$ of the time constants; $\sigma=$ standard deviation of the $\log$ of the time constants. 
original by multiplying all the transit times of the original one by a constant factor. Table 3 shows the moment ratios for two such spirograms, the second spirogram having transit times 1.5 times longer than the original. Only with truncation with respect to volume does the moment ratio correctly identify these two spirograms as having identical dispersion of time constants.

Table $3 \sqrt{ } a_{2} / a_{1}$ for a real spirogram and one generated from it with identical dispersion of time constants

$\begin{array}{llll}\text { Truncation } & \text { Truncation } & \text { Truncation } & \text { Truncation } \\ \text { at } 50 \% \text { FVC } & \text { at } 75 \% \text { FVC } & \text { at } & \text { at } \\ \text { three seconds } & \text { four seconds }\end{array}$

three seconds four seconds

\begin{tabular}{lllll}
\hline $\begin{array}{c}\text { Original } \\
\text { spirogram }\end{array}$ & 1.1719 & 1.2087 & 1.4432 & 1.5091 \\
$\begin{array}{c}\text { Generated } \\
\text { spirogram }\end{array}$ & 1.1719 & 1.2087 & 1.3543 & 1.4141 \\
\hline
\end{tabular}

We conclude from this that if the moments of truncated spirograms are to be compared, truncation must be with respect to volume if the comparisons are to be valid.

\section{Repeatability study}

\section{SUB JECTS}

Twenty-one untrained subjects (from hospital staff) were asked to participate. They were selected to give a balanced sex distribution ( 10 men and 11 women) and reasonable age span (range 21-59 years, mean $35 \cdot 0$, median 29 years). Eleven subjects were lifelong non-smokers, seven were ex-smokers (mean duration five years), and three were current smokers (mean duration 27 years). No subjects had any respiratory symptoms or were on any medication that would influence their pulmonary function. No-one was convalescing from a respiratory infection or developed symptoms during the study.

\section{METHOD}

After two test blows to familiarise them with the equipment, each subject performed five maximal forced expiratory manoeuvres at approximately the same time on each of five consecutive days. Smokers abstained from tobacco for two hours before testing. Flow was measured using a Fleisch pneumotachograph (diameter $60 \mathrm{~mm}$ ) fitted with a capacitance transducer whose signal was sampled every four milliseconds and A/D converted using a 12-bit converter. Flow trigger was set at $100 \mathrm{ml} / \mathrm{s}$. Volume was obtained by numerical integration using a computer. Instantaneous volume, flow, and elapsed time were stored in the computer when the incremental volume exceeded $20 \mathrm{ml}$ or the incremental time exceeded $0.1 \mathrm{~s}$, whichever was the sooner. Recording stopped after the subject had finished the blow. The system was calibrated each day before use through a range of flows using air saturated with water vapour at $37^{\circ} \mathrm{C}$. Repeat calibrations on the same day showed a variation in calibration factor of less than $0.3 \%$.

From the stored data a back extrapolation was computed from peak flow at constant peak flow to intercept the time axis at a new time zero. ${ }^{8}$ All time measurements were subsequently referenced to this new time zero. The end of the spirogram (that is, FVC) was defined as the largest volume recorded before flow was zero or negative. Sequential moments were derived in the following manner and stored in the computer.

If there are " $N$ " stored triplets (volume, flow, and time) of data ("N" is usually about 200 , range 100-300), let the " $n$ " th instantaneous volume, flow, and time be $V_{n}, F_{n}$ and $T_{n}$. The " $n$ " th volume increment $\Delta V_{n}=V_{n}-V_{(n-1)}$, the mean time taken for this volume increment to appear

$t_{n}=\frac{\left[T_{n}+T_{(n-1)}\right]}{2}$. The sequential " $r$ " th moment about the origin at the " $\mathrm{j}$ " th triplet of data is given by

$$
a_{r}=\frac{\sum_{n=1}^{n=j}\left[t_{n}{ }^{r} \times \Delta V_{n}\right]}{V_{j}}
$$

The truncated moments are standardised by the instantaneous volume rather than by the FVC so that the sequential truncated moments are not referenced by any event later than the truncation point. This scaling procedure does not influence the information contained in the moments.

Figure 1 shows sequential 1st $\left(\alpha_{1}\right)$ and 2 nd $\left(a_{2}\right)$ moments and moment ratio $\left(\sqrt{ } \alpha_{2} / \alpha_{1}\right)$ for a typical spirogram.

From the stored data all measurements at specified times or volumes were found by linear interpolation. For each blow 31 variables shown in table 4 were calculated and recorded.

\section{STATISTICS}

To estimate the within-person variability the mean within-person coefficient of variation (COV) for each of the 31 variables was calculated.

To estimate the ability of each variable to detect differences between the subjects an analysis of variance was performed on the natural logs of the results. The log transformation was necessary to standardise the variances as the results showed that for the majority of the variables the standard deviation was proportional to the mean. For each log variable the mean within-person variance $(W)$ was 


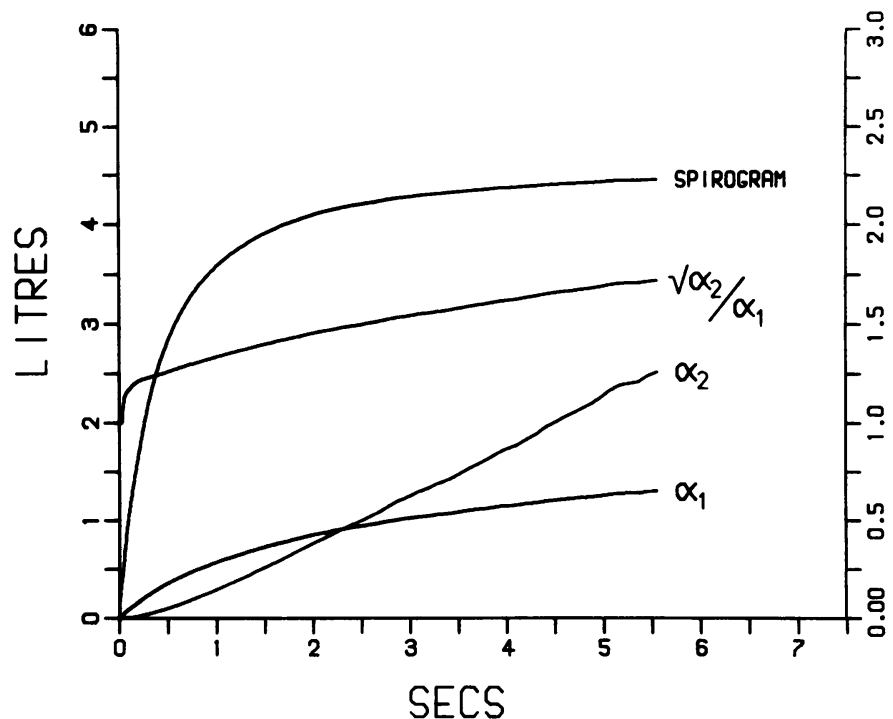

Fig 1 Graph of a typical spirogram with simultaneous $a_{1}(s), a_{2}\left(s^{2}\right)$, and $\sqrt{ } a_{2} / a_{1}$ plotted using the ordinate scale on the right.

Table 4 Thirty-one variables calculated and recorded from each spirogram

\begin{tabular}{|c|c|}
\hline 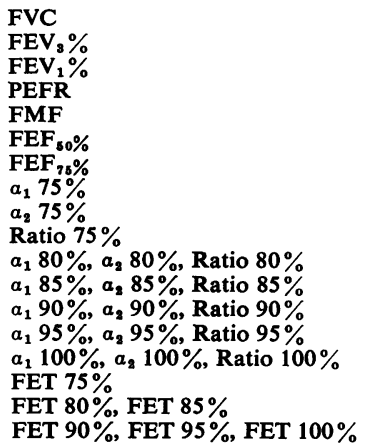 & $\begin{array}{l}\text { Forced vital capacity } \\
\text { Volume after three seconds expressed as percentage of FVC } \\
\text { Volume after one second expressed as percentage of FVC } \\
\text { Peak expiratory flow rate } \\
\text { Mean of all flows recorded between } 25 \% \text { and } 75 \% \text { of FVC } \\
\text { Instantaneous flow at } 50 \% \text { FVC ( } 50 \% \text { of VC expired) } \\
\text { Instantaneous flow at } 75 \% \text { FVC ( } 75 \% \text { of VC expired) } \\
\text { First moment at } 75 \% \text { FVC truncation ( } 75 \% \text { of VC expired) } \\
\text { Second moment at } 75 \% \text { FVC truncation } \\
\text { Ratio } \sqrt{ } a_{2} / a_{1} \text { at } 75 \% \text { FVC truncation }\end{array}$ \\
\hline
\end{tabular}

found, as was the between variance for the whole group (B). The ratio $\mathrm{B} / \mathrm{W}$ is an index of the ability for the variable to distinguish one subject from another. The $\mathrm{B} / \mathrm{W}$ ratio is the same as a signal-tonoise ratio. ${ }^{9}$

\section{RESULTS}

The results shown are derived by analysing the results from all five days together. Table 5 summarises the results for each variable with its group mean, group minimum and maximum, group standard deviation, mean within-person COV (all derived from the raw data) and $B / W$ ratio. Figure 2 illustrates the changes in mean within-person COV with progressively later truncation for the sequentially derived variables. The results for the conventional tests are plotted to the right on the same ordinate scale. All the sequentially derived variables are progressively less repeatable within individuals the later the truncation point. $\alpha_{2}$ and FET are unrepeatable and $\alpha_{1} 100 \%$ is only passably repeatable (COV $10.9 \%$ ). However the moment ratio up to $85 \%$ truncation is more repeatable than any of the other tests and up to $95 \%$ FVC truncation is still more repeatable than FVC.

Figure 3 is a plot of $B / W$ ratio against \% FVC truncation for the sequential variables with reference values for the conventional tests to the right. $\alpha_{1}, \alpha_{2}$, and FET are progressively less discriminatory the later the truncation point because the ensuing rise in within-person variance $(W)$ is not associated with a commensurate rise in between variance (B). The moment ratio is the only sequential variable whose $B / W$ ratio rises with later truncation. Its $B / W$ ratio is maximal at $85 \%$ FVC truncation and is maintained up to $95 \%$ FVC with a rapid decline thereafter. The moment ratio up to $95 \% \mathrm{FVC}$ is more discriminatory 
Table 5 Results for each variable with group mean, group minimum and maximum, group standard deviation (SD), mean within-person coefficient of variation $(C O V)$, between-person/within-person variance $(B / W)$

\begin{tabular}{|c|c|c|c|c|c|c|}
\hline & Group mean & Group min & Group max & Group $S D$ & $\begin{array}{l}\text { Mean within- } \\
\text { person } \\
\mathrm{COV} \%\end{array}$ & $B / W$ \\
\hline $\begin{array}{l}\text { FVC litres } \\
\text { FEV } \%_{3} \% \\
\text { FEV } 1 \% \\
\text { PEFR } 1 / \mathrm{s} \\
\text { FMF } 1 / \mathrm{s} \\
\text { FEF } \\
\text { FE\% } 1 / \mathrm{s} \\
a_{15} \% \mathrm{l} / \mathrm{s} \\
a_{1} 75 \% \mathrm{~s} \\
a_{1} 80 \% \mathrm{~s} \\
a_{1} 85 \% \mathrm{~s} \\
a_{1} 90 \% \mathrm{~s} \\
a_{1} 95 \% \mathrm{~s} \\
a_{1} 100 \% \mathrm{~s} \\
a_{2} 75 \% \mathrm{~s}^{2} \\
a_{2} 80 \% \mathrm{~s}^{2} \\
a_{2} 85 \% \mathrm{~s}^{2} \\
a_{2} 90 \% \mathrm{~s}^{2} \\
a_{2} 95 \% \mathrm{~s}^{2} \\
a_{2} 100 \% \mathrm{~s}^{2} \\
\sqrt{ } a_{2} / a_{1} 75 \% \\
\sqrt{ } a_{2} / a_{1} 80 \% \\
\sqrt{ } a_{2} / a_{1} 85 \% \\
\sqrt{ } a_{2} / a_{1} 90 \% \\
\sqrt{ } a_{2} / a_{1} 95 \% \\
\sqrt{ } a_{2} / a_{1} 100 \% \\
\text { FET } 75 \% \mathrm{~s} \\
\text { FET } 80 \% \mathrm{~s} \\
\text { FET } 85 \% \mathrm{~s} \\
\text { FET } 90 \% \mathrm{~s} \\
\text { FET } 95 \% \mathrm{~s} \\
\text { FET } 100 \% \mathrm{~s}\end{array}$ & $\begin{array}{l}4 \cdot 52 \\
94 \cdot 4 \\
77 \cdot 5 \\
9 \cdot 24 \\
3 \cdot 64 \\
3 \cdot 63 \\
1 \cdot 36 \\
0 \cdot 319 \\
0 \cdot 367 \\
0 \cdot 427 \\
0 \cdot 507 \\
0 \cdot 623 \\
0 \cdot 813 \\
0 \cdot 182 \\
0 \cdot 256 \\
0 \cdot 377 \\
0 \cdot 597 \\
1 \cdot 060 \\
2 \cdot 287 \\
1 \cdot 267 \\
1 \cdot 295 \\
1 \cdot 335 \\
1 \cdot 391 \\
1 \cdot 478 \\
1 \cdot 641 \\
1 \cdot 021 \\
1 \cdot 278 \\
1 \cdot 643 \\
2 \cdot 274 \\
3 \cdot 392 \\
6 \cdot 149\end{array}$ & $\begin{array}{l}2 \cdot 41 \\
76 \cdot 7 \\
54 \cdot 7 \\
5 \cdot 41 \\
1 \cdot 57 \\
1 \cdot 21 \\
0 \cdot 26 \\
0 \cdot 198 \\
0 \cdot 219 \\
0 \cdot 245 \\
0 \cdot 275 \\
0 \cdot 310 \\
0 \cdot 366 \\
0 \cdot 056 \\
0 \cdot 070 \\
0 \cdot 090 \\
0 \cdot 114 \\
0 \cdot 155 \\
0 \cdot 253 \\
1 \cdot 134 \\
1 \cdot 155 \\
1 \cdot 184 \\
1 \cdot 217 \\
1 \cdot 259 \\
1 \cdot 305 \\
0 \cdot 505 \\
0 \cdot 579 \\
0 \cdot 684 \\
0 \cdot 841 \\
1 \cdot 129 \\
1 \cdot 900\end{array}$ & $\begin{array}{c}7 \cdot 86 \\
100 \cdot 0 \\
93 \cdot 6 \\
14 \cdot 75 \\
6 \cdot 25 \\
7 \cdot 07 \\
3 \cdot 40 \\
0 \cdot 681 \\
0 \cdot 836 \\
1 \cdot 031 \\
1 \cdot 284 \\
1 \cdot 616 \\
2 \cdot 093 \\
0 \cdot 989 \\
1 \cdot 560 \\
2 \cdot 488 \\
4 \cdot 095 \\
7 \cdot 086 \\
13 \cdot 279 \\
1 \cdot 461 \\
1 \cdot 509 \\
1 \cdot 552 \\
1 \cdot 663 \\
1 \cdot 923 \\
2 \cdot 184 \\
2 \cdot 811 \\
3.696 \\
4 \cdot 978 \\
6 \cdot 698 \\
9 \cdot 344 \\
15 \cdot 172\end{array}$ & $\begin{array}{l}1 \cdot 22 \\
5 \cdot 0 \\
7 \cdot 7 \\
2 \cdot 14 \\
1 \cdot 01 \\
1 \cdot 10 \\
0 \cdot 65 \\
0 \cdot 088 \\
0 \cdot 107 \\
0 \cdot 134 \\
0 \cdot 172 \\
0 \cdot 299 \\
0 \cdot 319 \\
0 \cdot 133 \\
0 \cdot 209 \\
0 \cdot 341 \\
0 \cdot 586 \\
1 \cdot 086 \\
2 \cdot 298 \\
0.056 \\
0 \cdot 067 \\
0 \cdot 083 \\
0 \cdot 109 \\
0 \cdot 146 \\
0 \cdot 189 \\
0 \cdot 376 \\
0 \cdot 519 \\
0 \cdot 734 \\
1 \cdot 110 \\
1 \cdot 763 \\
2 \cdot 954\end{array}$ & $\begin{array}{r}3 \cdot 3 \\
1 \cdot 7 \\
2 \cdot 4 \\
4 \cdot 1 \\
6 \cdot 5 \\
8 \cdot 6 \\
12 \cdot 7 \\
5 \cdot 6 \\
6 \cdot 1 \\
6 \cdot 8 \\
7 \cdot 8 \\
9 \cdot 3 \\
10 \cdot 9 \\
12 \cdot 8 \\
14 \cdot 4 \\
16 \cdot 6 \\
20 \cdot 4 \\
25 \cdot 4 \\
29 \cdot 2 \\
1 \cdot 3 \\
1 \cdot 4 \\
1 \cdot 7 \\
2 \cdot 1 \\
2 \cdot 8 \\
4 \cdot 1 \\
8 \cdot 8 \\
9 \cdot 8 \\
11 \cdot 3 \\
13 \cdot 6 \\
15 \cdot 9 \\
17 \cdot 9\end{array}$ & $\begin{array}{r}58 \cdot 7 \\
8 \cdot 1 \\
14 \cdot 5 \\
25 \cdot 5 \\
17 \cdot 3 \\
11 \cdot 2 \\
13 \cdot 4 \\
15 \cdot 0 \\
14 \cdot 6 \\
13 \cdot 2 \\
11 \cdot 8 \\
10 \cdot 5 \\
9 \cdot 4 \\
14 \cdot 7 \\
13 \cdot 3 \\
12 \cdot 0 \\
10 \cdot 7 \\
9 \cdot 7 \\
8 \cdot 3 \\
9 \cdot 2 \\
10 \cdot 2 \\
10 \cdot 6 \\
10 \cdot 3 \\
9 \cdot 6 \\
6 \cdot 5 \\
10 \cdot 9 \\
10 \cdot 7 \\
10 \cdot 1 \\
9 \cdot 5 \\
8 \cdot 5 \\
6 \cdot 1\end{array}$ \\
\hline
\end{tabular}

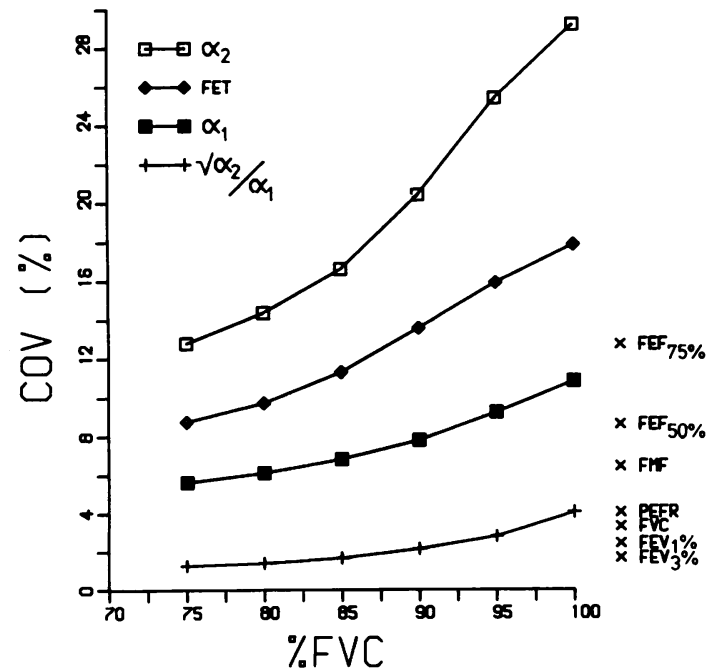

Fig 2 Relationship between mean within-person (COV) and $\%$ FVC truncation for sequentially derived variables compared with conventional tests.

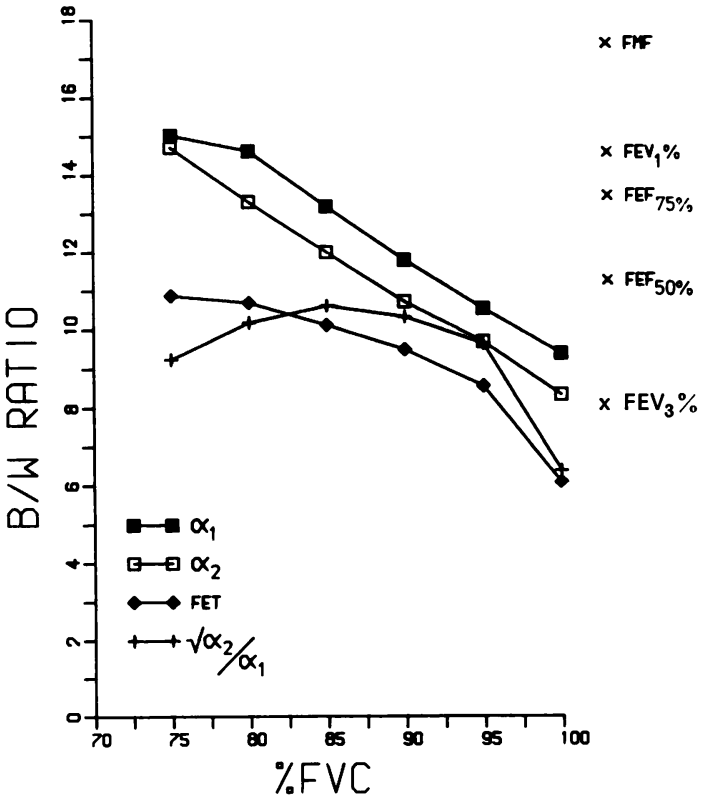

Fig 3 Relationship between $B / W$ ratio and $\% F V C$ truncation for sequentially derived variables compared with conventional tests. 
than $\mathrm{FEV}_{3} \%$ but is less so than $\mathrm{FEF}_{75 \%}, \mathrm{FEF}_{50 \%}$, and FMF.

Table 6 shows a correlation matrix of " $r$ " values for relevant variables. We have correlated $\alpha_{1}$ and the moment ratio at the earliest truncation ( $75 \%$ FVC), intermediate truncation ( $90 \% \mathrm{FVC})$ and no truncation $(100 \% \mathrm{FVC})$ with indices of intermediate and late events $\left(\mathrm{FEV}_{1} \%, \mathrm{FEF}_{75} \%, \mathrm{FEV}_{3} \%\right)$.

The first moment even at $100 \%$ FVC is highly correlated with $\mathrm{FEV}_{1} \%$. With later truncation the moment ratio becomes progressively less well correlated with $\mathrm{FEV}_{1} \%$ and up to $90 \%$ truncation more correlated with $\mathrm{FEF}_{75} \%$ and $\mathrm{FEV}_{3} \%$.

\section{Discussion}

Our finding that truncation of spirograms must be with respect to volume is a serious limitation of moment analysis of the spirogram. Most spirograms obtained are in a sense already truncated as they are not truly asymptotic. The observed FVC is not the theoretical terminal volume (TTV) achievable if the expiration could have continued to infinite time. Different factors operate in different subjects to determine the end of the spirogram. ${ }^{10}$ Factors involved include effort, chest wall mechanics, airway closure, and breath-hold time.

Comparing moments derived to $100 \% \mathrm{FVC}$ is introducing an unknown error as this point is at an unknown percentage of TTV, and it is with respect to TTV that truncation must be made if comparisons are to be valid. By looking at fig 1 it can be deduced that this error is maximal at $100 \%$ FVC and is reduced by earlier truncation. If the difference between FVC and TTV was $100 \mathrm{ml}$, the absolute error in defining $95 \%$ FVC truncation would be 95 $\mathrm{ml}$. From fig 1 it can be seen that this would cause significant errors in defining the moments and moment ratio. However the error of $90 \mathrm{ml}$ in defining the $90 \%$ truncation point would cause much smaller errors as $90 \%$ FVC in this case falls on the bend of the spirogram. Earlier truncation than this further reduces the errors. Hence comparing the moments with no truncation or truncation in the terminal flatter part of a spirogram introduces the largest errors. If a recorded spirogram is not asymptotic in character then the inevitable truncation errors will be unacceptably large despite earlier truncation. However the challenge for the study of the moments of the spirogram is to detect early changes from normality so that the restriction of this analysis to essentially asymptotic spirograms is an acceptable limitation of its use. All the subjects in our study had spirograms which were asymptotic in character.

Permutt and Menkes ${ }^{7}$ appreciated the problems of the inevitable truncation of recorded spirograms when considering the moments of the spirogram. By making certain assumptions about the way an expiration might continue to infinite time, they developed a mathematical model of forced expiration to overcome truncation errors. From this model they could derive a predicted value for moment ratio at TTV. Although this is the most sensitive index of dispersion of time constants of lung emptying it is not directly measurable. Despite the truncation errors discussed by us, Webster et al ${ }^{11}$ found that $\alpha_{1}$ $100 \%$ could detect differences between young smokers and young non-smokers when $\mathrm{FEV}_{1} \%$ and FEF $_{75} \%$ could not. We undertook this study to see if with earlier truncation to reduce truncation errors, the moments and moment ratio retain discriminatory ability.

We have found $\alpha_{1} 75 \%$ to be as good a discriminator between our subjects as $\mathrm{FEV}_{1} \%$ but it has a higher $\operatorname{COV}(5.6 \%$ versus $2.4 \%)$ and correlates closely with $\mathrm{FEV}_{1} \%(\mathrm{r}=-0.90, \mathrm{p}<0.001) . \alpha_{1}$ $100 \%$ also correlates closely with $\mathrm{FEV}_{1} \%(\mathrm{r}=-0.89$, $\mathrm{p}<0.001)$ but is less discriminatory and has a higher $\operatorname{COV}(10.9 \%)$. Both these findings and the truncation errors at $100 \%$ FVC make us feel that $\alpha_{1} 100 \%$ is unlikely to supersede $\mathrm{FEV}_{1} \%$. In addition its sensitivity to late events is limited by its high correlation with $\mathrm{FEV}_{1} \%$. Whether $\alpha_{1} 75 \%$ is better than $\mathrm{FEV}_{1} \%$ in a wider clinical sense remains to be proven. We have found FET to have important discriminatory ability but as has been found previously, ${ }^{45}$ it is too unrepeatable to be of general use.

We and others ${ }^{6} 711$ have exclusively analysed the spirogram about the origin whereas some workers ${ }^{2} 3$ have analysed the spirogram about the mean transit time $\left(\alpha_{1} 100 \%\right)$ to derive the second moment about the mean $\left(\mu_{2}\right)$. As there are errors in comparing $\alpha_{1}$

Table 6 Correlation matrix for $r$ values

\begin{tabular}{|c|c|c|c|c|c|c|c|c|}
\hline & $F E F_{75 \%}$ & $F E V_{3} \%$ & $F E V_{1} \%$ & $\sqrt{ } a_{2} / a_{1} 100 \%$ & $\alpha_{1} 100 \%$ & $\sqrt{ } a_{2} / a_{1} 90 \%$ & $a_{1} 90 \%$ & $\sqrt{ } a_{2} / a_{1} 75 \%$ \\
\hline $\begin{array}{l}a_{1} 75 \% \\
\sqrt{ } a_{2} / a_{1} 75 \% \\
a_{1} 90 \% \\
\sqrt{ } a_{2} / a_{1} 90 \% \\
a_{1} 100 \% \\
\sqrt{ } a_{2} / a_{1} 100 \% \\
F E V_{1} \% \\
F E V_{3} \%\end{array}$ & $\begin{array}{r}-0.25 \\
-0.79 \\
-0.51 \\
-0.86 \\
-0.66 \\
-0.64 \\
0.57 \\
0.72\end{array}$ & $\begin{array}{r}-0.66 \\
-0.85 \\
-0.87 \\
-0.86 \\
-0.97 \\
-0.67 \\
0.82\end{array}$ & $\begin{array}{l}-0.90 \\
-0.80 \\
-0.94 \\
-0.61 \\
-0.89 \\
-0.32\end{array}$ & $\begin{array}{l}0.00 \\
0.51 \\
0.27 \\
0.81 \\
0.57\end{array}$ & $\begin{array}{l}0.78 \\
0.84 \\
0.94 \\
0.79\end{array}$ & $\begin{array}{l}0.28 \\
0.85 \\
0.59\end{array}$ & $\begin{array}{l}0.93 \\
0.79\end{array}$ & 0.57 \\
\hline
\end{tabular}


$100 \%$ from one subject to another, this makes analysis about $\alpha_{1} \quad 100 \%$ less meaningful. Since $\alpha_{1}$ $100 \%$ has a COV of $10.9 \%$, one would expect $\mu_{2}$ to be more variable within individuals than $\alpha_{2} 100 \%$. By analysing our data appropriately we found $\mu_{2}$ to have a COV of $32.9 \%$ compared with $29.2 \%$ for $\alpha_{2} 100 \%$.

The moment ratio $\left(\sqrt{ } a_{2} / a_{1}\right)$ is an index of the dispersion of the time constants of the spirogram. To effect a given rise in moment ratio, the early part of the spirogram must be steeper or the later part of the spirogram must be flatter or both. For changes in the early part of the spirogram alone to account for a rise in moment ratio, peak flow rapidly becomes unphysiological, so far practical purposes a rise in moment ratio is caused by changes in the later part of the spirogram - that is, a reduction of flow in the later part of the spirogram relative to the early part.

The moment ratio at progressively later truncation is less well correlated with $\mathrm{FEV}_{1} \%$ (table 6) and is more sensitive to terminal events. If a moment ratio of a spirogram is greater than that of a single exponential at a given truncation point, then the maximum expiratory flow-volume curve (MEFVC) must be concave upwards and if it is less than that of a pure exponential the MEFVC will be convex upwards. With later truncation the moment ratio is insensitive to early events and so it is a descriptor of the curvilinearity of only the terminal part of the MEFVC.

The moment ratio is highly reproducible and is sensitive to events late in the spirogram so it may have advantages over $\mathrm{FEF}_{75} \%$ and FET which are less reproducible, have a wide normal range, and are of limited value when applied to individual subjects as a screening test. However three things must be considered in selecting optimum truncation point for the moment ratio: (1) the later the truncation point the less dependent the moment ratio is on early events; (2) its $\mathrm{B} / \mathrm{W}$ ratio is maximal at $85 \% \mathrm{FVC}$ and falls off sharply after $95 \%$ FVC; and (3) truncation errors are minimised by earlier truncation. We feel that $90 \%$ truncation may well be optimal for the moment ratio and truncation earlier than $85 \%$ FVC and at $100 \%$ FVC would be unacceptable.

In our group of subjects ratio $90 \%$ is less discriminatory than $\mathrm{FEF}_{\mathbf{5 0}} \%, \mathrm{FEF}_{\mathbf{7 5}} \%$, and $\mathrm{FMF}$, but these flow measurements are dependent on size and age. ${ }^{12}$ Ratio $90 \%$ has no significant correlation with height $(r=-0.01)$ or PEFR $(r=0.01)$ in our subjects, and our small sample precludes separation of the effects of age and smoking on moment ratio. As ratio $90 \%$ is influenced by events later in the spirogram than are $\mathrm{FEF}_{50} \%, \mathrm{FEF}_{75} \%$, and $\mathrm{FMF}$, it is likely to be discriminating between our subjects with an emphasis different from these flow measurements.

We conclude that problems associated with truncated and untruncated spirograms in moment analysis have not been fully appreciated previously and these problems are reduced by earlier truncation. This truncation must be with respect to volume for valid comparisons of moments to be made. Moment ratio at $90 \%$ FVC truncation has many features suggesting its merit as a test of lung function and its further study is warranted.

We thank Mr D Grove of the Department of Statistics, University of Birmingham for his invaluable advice and mathematical proof of our observations on truncation. We acknowledge the University of Birmingham Faculty of Medicine's Rowbotham Bequest and Scott-Moncrieff Bequest for financial support.

\section{References}

${ }^{1}$ Jordanoglou J, Koursouba E, Lalenis C, Gotsis T, Kontos J, Gardikas C. Effective time of the forced expiratory spirogram in health and airways obstruction. Thorax 1979;34:187-93.

${ }^{2}$ Liang A, Macfie AE, Harris EA, Whitlock RML. Transittime analysis of the forced expiratory spirogram during clinical remission in juvenile asthma. Thorax 1979;34: 194-9.

${ }^{3}$ Neuburger N, Levison H, Kruger K. Transit time analysis of forced expiratory vital capacity in cystic fibrosis. $\mathbf{A m}$ Rev Respir Dis 1976;114:753-9.

${ }^{4}$ Cochrane GM, Prieto F, Clark TJH. Intrasubject variability of maximal expiratory flow volume curve. Thorax 1977; 32:171-6.

${ }^{5}$ Macdonald JB, Cole TJ, Seaton A. Forced expiratory time -its reliability as a lung function test. Thorax 1975;30: 554-9.

- Tockman M, Menkes H, Cohen B, Permutt S, Benjamin J, Ball WC, Tonascia J. A comparison of pulmonary function in male smokers and non-smokers. Am Rev Respir Dis 1976;114:711-22.

7 Permutt S, Menkes HA. Spirometry: analysis of the forced expiration within the time domain. The lung in transition between health and disease. In. Macklem P, Permutt S, eds. Lung biology in health and disease. Volume 12. New York: Marcel Dekker, 1979.

${ }^{8}$ Smith AA, Gaensler EA. Timing of forced expiratory volume in one second. Am Rev Respir Dis 1975;112: 882-5.

9 Macdonald JB, Cole TJ. The flow-volume loop: reproducibility of air and helium-based tests in normal subiects. Thorax 1980;35:64-9.

${ }^{10}$ Davis C, Campbell EJM, Openshaw P, Pride NB, Woodroof G. Importance of airway closure in limiting maximal expiration in normal man. J Appl Physiol 1980; 48:695-701.

11 Webster PM, Zamel N, Bryan AC, Kruger K. Volume dependence of instantaneous time constants derived from maximal expiratory flow-volume curves. Am Rev Respir Dis 1977;115:805-10.

12 Knudson RJ, Slatin RC, Lebowitz MD, Burrows B. The maximal expiratory flow-volume curve. Normal standards, variability and effects of age. Am Rev Respir Dis 1976;113:587-600. 